\title{
Roles of Acetone-Conditioning and Lipid in Sorption of Organic Contaminants
}

Xilong Wang and Baoshan Xing*

Department of Plant, Soil and Insect Sciences, University of Massachusetts, Amherst, Massachusetts 01003

Supporting Information:

Total number of pages: $\quad 5$

Number of tables: $\quad 2$

Number of figures: $\quad 6$

*Corresponding author (Baoshan Xing). Tel: (413) 545-5212; Fax: (413) 545-3958; Email: $\underline{\text { bx@ pssci.umass.edu }}$ 
TABLE S1. Selected Physicochemical Properties of the Chemicals Used in this Study

$\begin{array}{llcccccc}\text { chemicals } & \text { abbreviation } & \text { MW } & \log K_{\mathrm{ow}} & S_{\mathrm{w}} & \text { density } & \text { MV } & \mathrm{p} K_{\mathrm{a}} \\ \text { phenanthrene } & \text { Phen } & 178.2 & 4.46 & 1.15 & 1.063 & 169.5 & \\ \text { 1-naphthol } & \text { 1-Naph } & 144.2 & 2.70 & 866 & 1.10 & 96.6 & 9.34\end{array}$

MW: molecular weight $(\mathrm{g} / \mathrm{mol}) ; K_{\text {ow }}$ : octanol-water partition coefficient; $S_{\mathrm{w}}$ : aqueous solubility $(\mathrm{mg} / \mathrm{L})$; density $\left(\mathrm{g} / \mathrm{cm}^{3}\right) ; \mathrm{MV}$ : molecular volume $\left(\AA^{3}\right) ; \mathrm{p} K a$ : negatively log-transformed acid dissociation constant.

TABLE S2. Freundlich and Linear Model Parameters for Sorption of Phen and 1-Naph by Lipid, Original and Treated Peat Soil, Humic Acids and Humin.

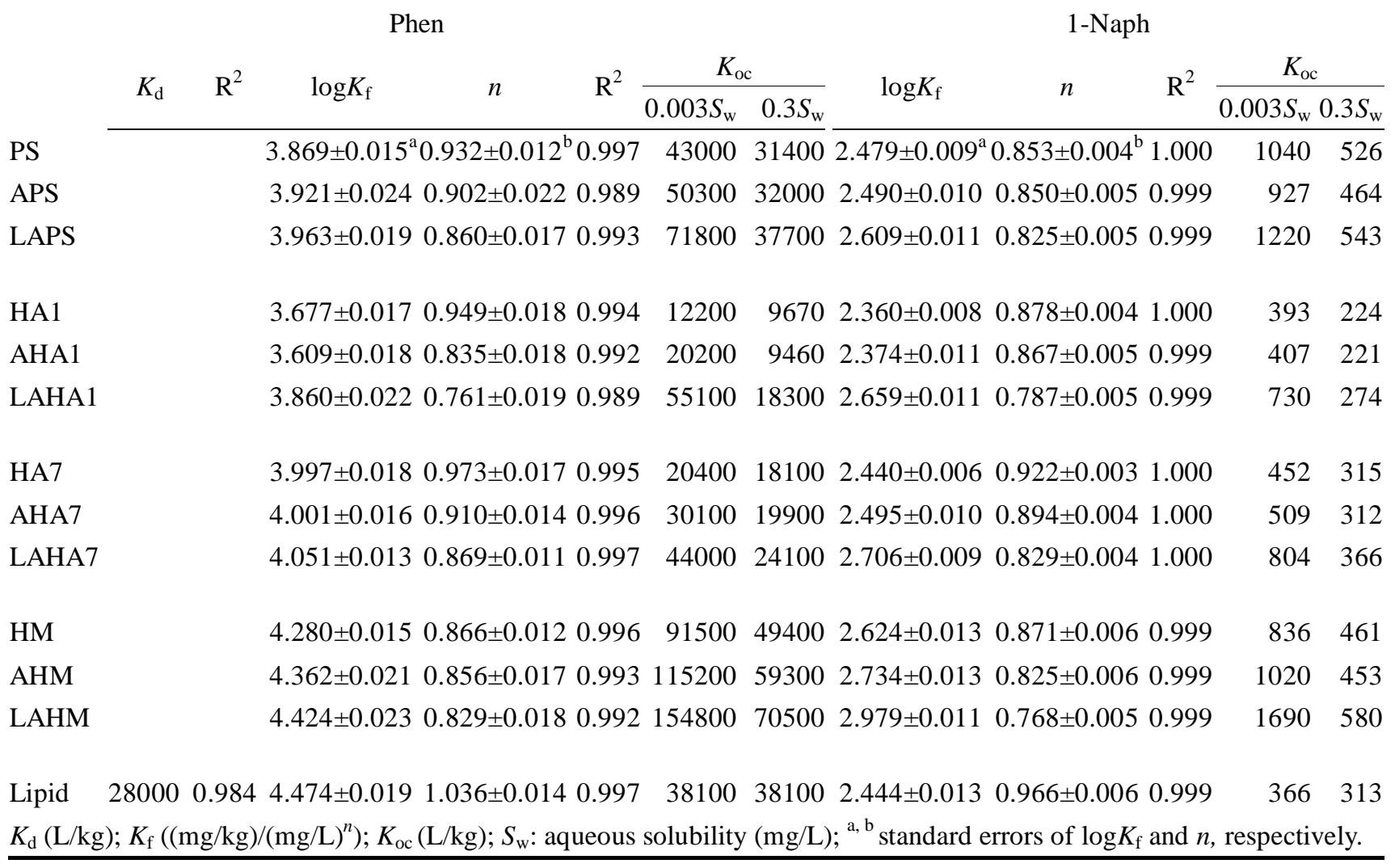




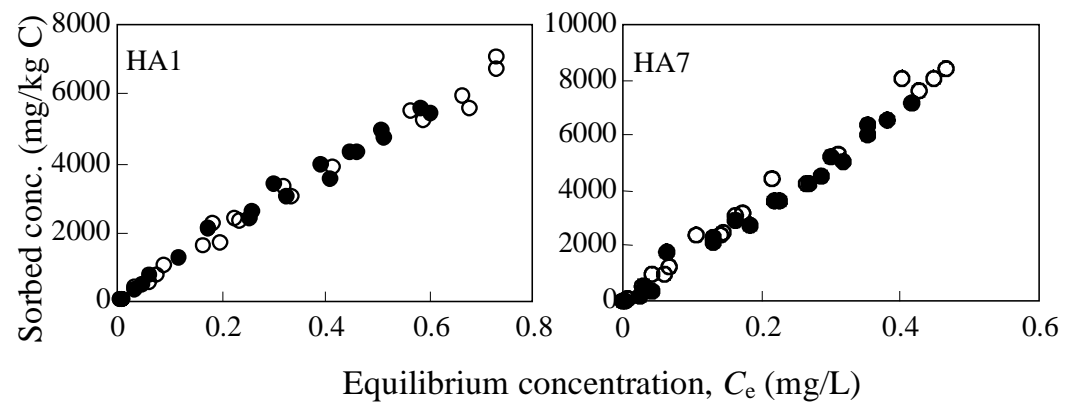

FIGURE S1. Sorption of Phen by HA1 and HA7 in the presence and absence of $0.1 \%$ (v/v) chloroform in the test solution. Open circles refer to Phen sorption in the absence of chloroform and the closed ones represent that in the presence of chloroform. The figures show no chloroform effect on sorption.

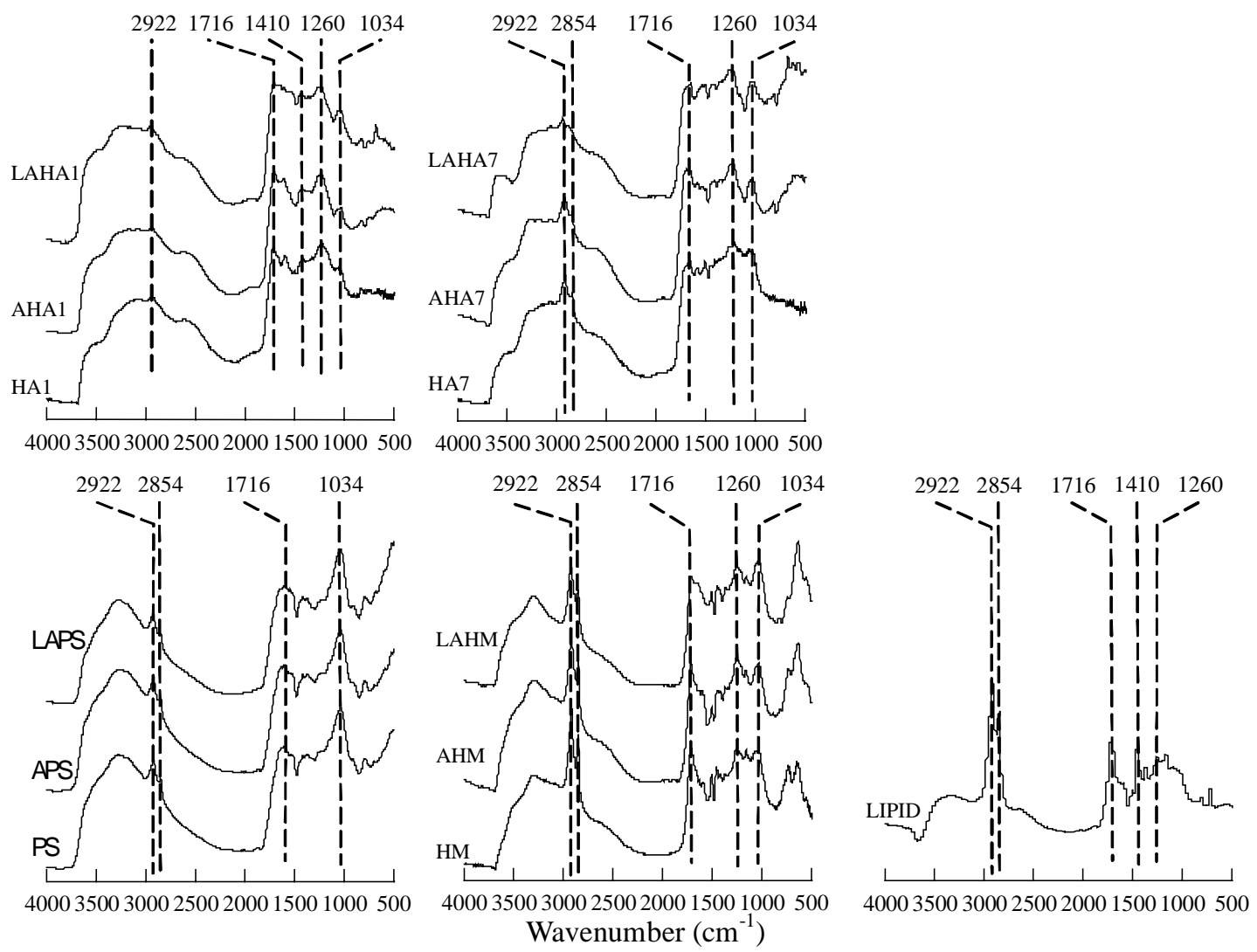

FIGURE S2. DRIFT spectra of lipid, original and treated peat soil, HAs and HM. 


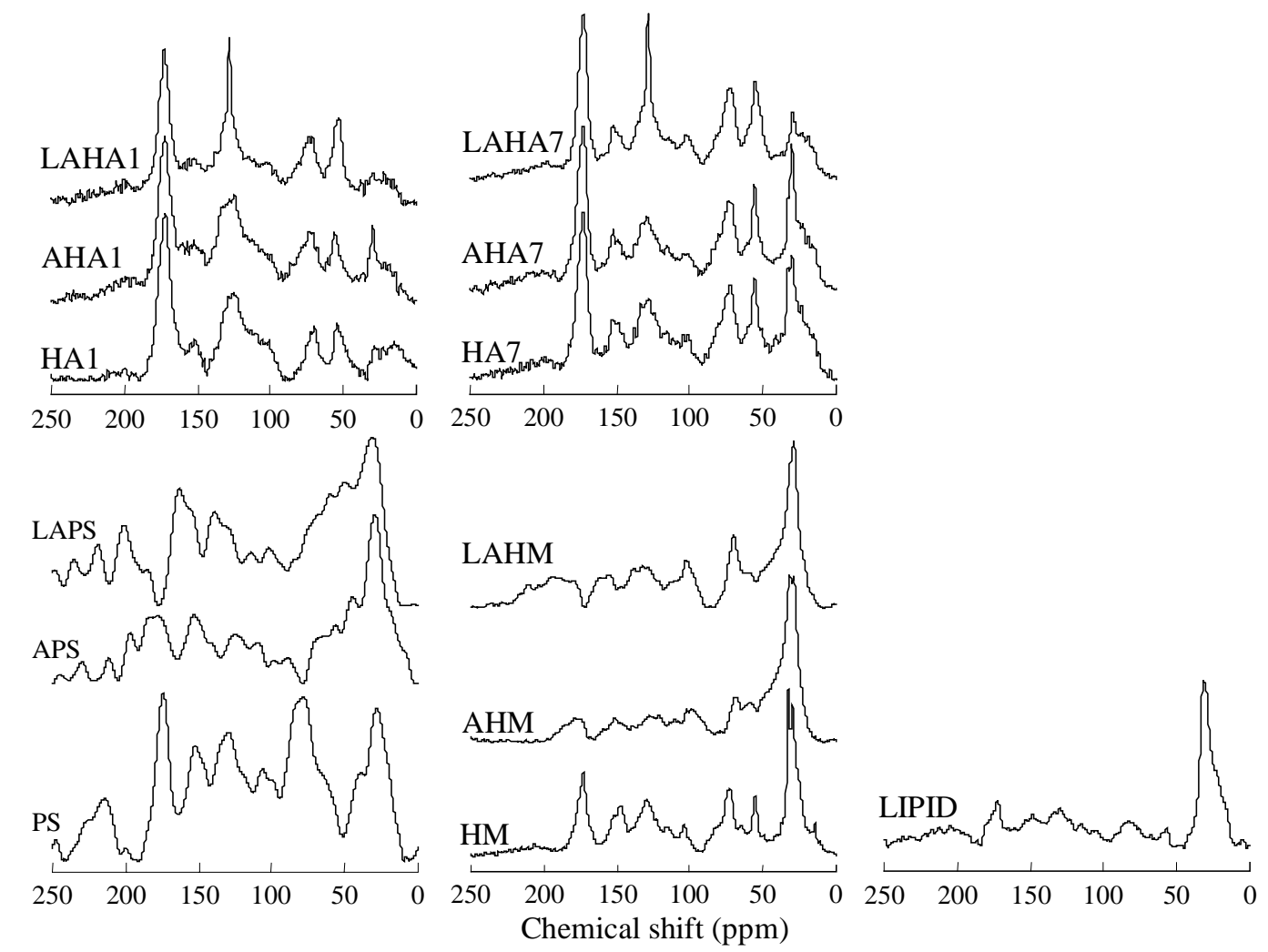

FIGURE S3. Solid-state ${ }^{13} \mathrm{C}$ NMR spectra of lipid, original and treated peat soil, HAs and HM.

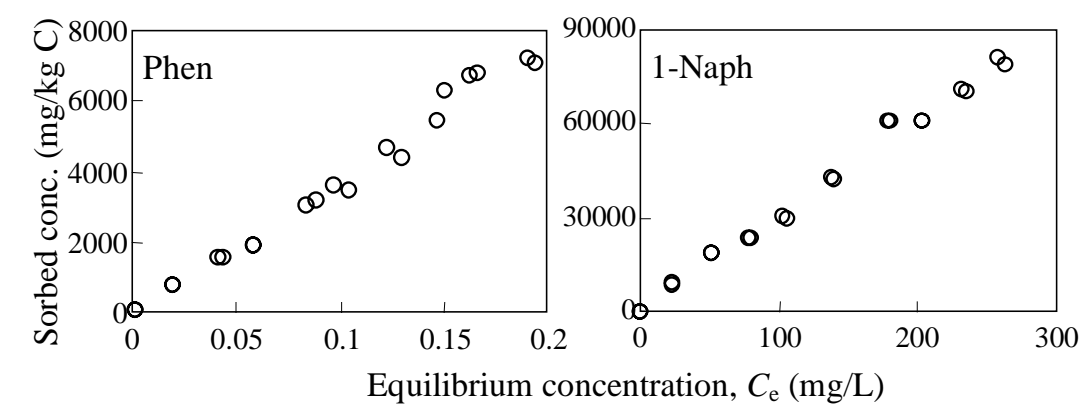

FIGURE S4. Sorption isotherms of Naph and 1-Naph by lipid. 

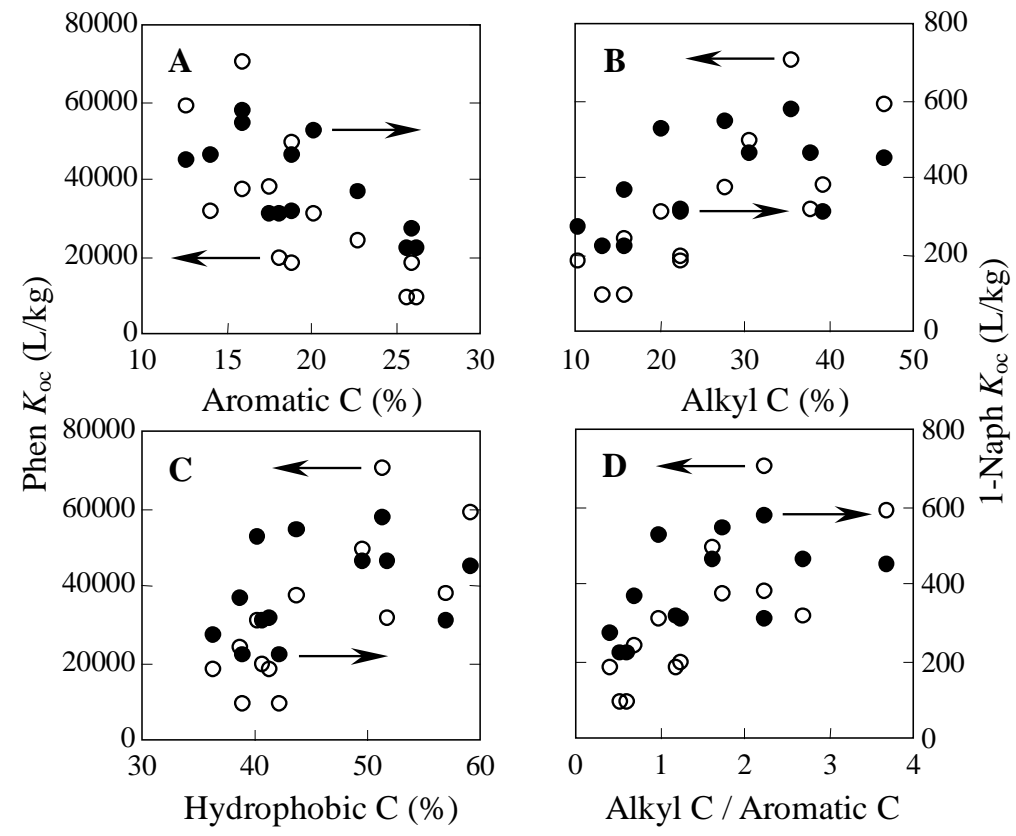

FIGURE S5. Relationship between $K_{\mathrm{oc}}$ and aromatic C (A), alkyl C (B), hydrophobic C (C) content as well as alkyl C/Aromatic C (D) of SOM. Open symbols are for Phen and closed ones are for 1-Naph.

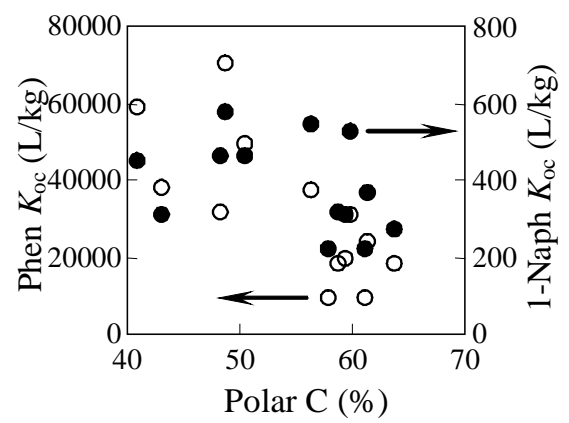

FIGURE S6. Relationship between $K_{\mathrm{oc}}$ and polar C content of SOM. Open symbols are for Phen and closed ones are for 1-Naph. 